\title{
Impact of antibiotic resistance in the management of ocular infections: the role of current and future antibiotics
}

This article was published in the following Dove Press journal:

Clinical Ophthalmology

15 September 2009

Number of times this article has been viewed

\author{
Joseph S Bertino Jr $r^{1,2}$ \\ 'College of Physicians and Surgeons, \\ Columbia University, New York, \\ NY, USA; ${ }^{2}$ Principal, Bertino \\ Consulting, Schenectady, NY, USA
}

Correspondence: Joseph S Bertino Jr Principal, Bertino Consulting, 3078 New Williamsburg Drive, Schenectady, NY I 2303, USA

Tel +l 518-280-1378

Email sbertino@ix.netcom.com
Purpose: This article reviews the effects of the increase in bacterial resistance on the treatment of ocular infections.

Design: Interpretive assessment.

Methods: Literature review and interpretation.

Results: Ocular bacterial infections include conjunctivitis, keratitis, endophthalmitis, blepharitis, orbital cellulitis, and dacryocystitis. Treatment for most ocular bacterial infections is primarily empiric with broad-spectrum antibiotics, which are effective against the most common bacteria associated with these ocular infections. However, the widespread use of broad-spectrum systemic antibiotics has resulted in a global increase in resistance among both Gram-positive and Gram-negative bacteria to a number of the older antibiotics as well as some of the newer fluoroquinolones used to treat ophthalmic infections. Strategies for the prevention of the increase in ocular pathogen resistance should be developed and implemented. In addition, new antimicrobial agents with optimized pharmacokinetic and pharmacodynamic properties that have low toxicity, high efficacy, and reduced potential for the development of resistance are needed.

Conclusions: New antimicrobial agents that treat ocular infections effectively and have a low potential for the development of resistance could be a part of strategies to prevent the global increase in ocular pathogen resistance.

Keywords: ocular infections, emerging pathogen drug resistance, fluoroquinolones, besifloxacin

\section{Introduction}

Ophthalmic infections can cause damage to structures of the eye, which can lead to vision loss and even blindness if left untreated. ${ }^{1}$ The effective use of antibiotics to treat ophthalmic infections requires an understanding of the disease and the pharmacokinetics and pharmacodynamics of the drugs used for the treatment. ${ }^{1,2}$ The most common ocular infection seen by primary care physicians worldwide is bacterial conjunctivitis, which is self-limiting and largely presents as an acute infection. ${ }^{3,4}$ Bacterial keratitis, an infection of the cornea often associated with contact lens wear, ocular trauma, or ocular surface disease, is less common but poses a risk of loss of vision. ${ }^{5-8}$ Endophthalmitis is a rare but potentially sight-threatening infective complication of intraocular surgery (primarily cataract), intravitreal injections, and ocular trauma. ${ }^{9,10}$ Bacterial blepharitis is an inflammation of the eyelids, particularly at the lid margins, that may be associated with a low-grade staphylococcal bacterial infection. ${ }^{11}$ Orbital cellulitis and other periorbital infections can be caused by a variety of organisms, including bacteria, and occurs as a complication of surgery, nonsurgical trauma, or the retention of a foreign body. ${ }^{12}$ Dacryocystitis, or infections of the lacrimal sac, are common at all 
ages and occur due to acquired or congenital obstruction of nasolacrimal duct. ${ }^{13}$ Although treatment guidelines for these ocular infections recommend that laboratory culture and smear tests be conducted, when possible, for determination of the causative pathogens, ${ }^{14}$ in practice the initial choice of antibiotic therapy is generally made without knowing the identity or susceptibility of the ocular pathogen. ${ }^{1,9,15,16}$ Broad-spectrum antibiotic therapy for bacterial infections is initially used in order to prevent a decline in vision or permanent vision loss that may require surgical intervention. ${ }^{9,16,17}$ Endophthalmitis, bacterial keratitis, and orbital cellulitis require aggressive initial broad-spectrum antibiotic therapy, which can subsequently be tapered or modified after the results from laboratory culture and smear tests are obtained. ${ }^{18}$ In this context, it must be noted that most ophthalmic antibiotics are approved for bacterial conjunctivitis only, with few indicated for keratitis and none for endophthalmitis. ${ }^{19}$

Several therapeutic classes of antibiotic agents are available for ophthalmic indications. These agents differ in their mechanism of action, coverage of important pathogens, and bactericidal versus bacteriostatic effects. The penicillins, cephalosporins, aminoglycosides, and fluoroquinolones are bactericidal agents (ie, kill bacteria) ${ }^{20}$ and are generally used to treat ocular infections. Bacteriostatic drugs like tetracyclines, macrolides, chloramphenicol, and sulfonamides, which inhibit bacterial growth, are used in cases in which there is a specific benefit or an allergy issue. Antibiotics can be used systemically or topically to control ocular infection. Topically applied antibiotics are more effective in achieving rapid, high concentrations of the antibiotic at the site of infection compared to systemically administered antibiotics. Frequent or inappropriate, systemic long-term use of an antibiotic may result in the development of bacterial antibiotic resistance. Therefore, topical administration of antibiotics may be a better choice, although the occurrence of drug resistance with topical antibiotics used for prolonged periods has been reported. ${ }^{1}$ Ophthalmic antibiotics are generally formulated as solutions or suspensions, but some are also available as ointments (eg, erythromycin, polymyxin, or bacitracin). Ointments theoretically provide prolonged exposure, since they do not get removed from the site of infection as rapidly as ophthalmic solutions/suspensions do because of rapid tear film turnover. ${ }^{1}$ However, hydrophilic antibiotics often crystallize within the ointment base, which may impact their release, available concentration, and effectiveness. ${ }^{1}$ Other factors that affect the exposure of ocular drugs include the integrity of the corneal epithelial barrier, inflammation of the ocular tissues, and the microtoxicity associated with the use of preservatives. ${ }^{1}$ Thus, the clinician may choose from a number of formulations of agents based on the location and severity of the infection, comorbidities, and the safety and tolerability of the antibiotic as well as bacterial susceptibility.

Rapid use of antibiotics for severe ocular infections is routine in ophthalmic practice, as pathogenesis of ocular bacteria results in release of toxins and degradative enzymes that can damage the integrity of ocular tissues and cause sight-damaging sequelae. Although older ophthalmic antibiotics such as chloramphenicol, sulfonamides, polymyxins, bacitracin, and aminoglycosides and early-generation fluoroquinolones are still prescribed, they are less effective than the advanced-generation fluoroquinolones for treating ocular infections because of a limited spectrum of activity and/or the development of pathogen resistance. ${ }^{21,22}$ The advanced-generation fluoroquinolones (eg, moxifloxacin and gatifloxacin) have a broader spectrum of activity and are more effective against common ocular pathogens. ${ }^{23}$

The development of bacterial resistance to specific antibiotics is an important consideration for clinicians treating ocular infections. Bacterial resistance has been emerging worldwide, likely due to widespread and inappropriate dosing of broad-spectrum antibiotics for systemic infections, exacerbated by inadequate compliance to full treatment duration. ${ }^{24}$ Of note, the Ocular Tracking Resistance in the U.S. Today (TRUST) program, which annually evaluates the in vitro susceptibility of Staphylococcus aureus, Streptococcus pneumoniae, and Haemophilus influenzae to a number of ophthalmic antibiotics in national samples of ocular isolates, reported a $12.1 \%$ increase in the incidence of methicillin-resistant $S$. aureus (MRSA) strains from January 2000 to December 2005, with more than $80 \%$ of MRSA resistant to fluoroquinolones. ${ }^{25,26}$ While these numbers are alarming, one limitation of studies on the emergence of resistance among ocular pathogens is that the determination of bacterial susceptibility to ophthalmic antibiotics is typically based on systemic drug exposure breakpoints, the concentrations at which bacterial isolates are deemed susceptible or resistant to a particular drug. ${ }^{27,28}$ The data used to determine breakpoints are derived from systemic dosing and the average concentration of drugs in tissues after systemic administration. Since topical administration produces a higher concentration of antibiotic in ocular tissues than that achieved following systemic therapy, these breakpoints, defined by the Clinical and Laboratory Standards Institute (CLSI), do not apply. ${ }^{27}$ Nevertheless, as discussed later in this review, there 
are many reports of clinical treatment failure due to ocular pathogen drug resistance. These reports highlight the need to reevaluate and implement improved treatment guidelines for the prevention of pathogen resistance to ocular anti-infective therapies, ${ }^{26,27}$ and the need to develop new antibiotics with greater efficacy, lower toxicity, and lower resistance potential than older agents. ${ }^{29}$

\section{Ocular infections and current treatment options \\ Bacterial conjunctivitis}

Bacterial conjunctivitis, or red eye, which involves inflammation of the conjunctival mucosa, is more common in young children and the elderly than in other age groups. ${ }^{3}$ The etiology of conjunctivitis can be allergic, toxic, or infectious. Symptoms of bacterial conjunctivitis include a purulent discharge around the eye, hyperemia, and a burning or stinging sensation. ${ }^{3,15}$ The most common causal pathogens in bacterial conjunctivitis are $S$. aureus, $S$. pneumoniae, and H. influenzae. Staphylococcus epidermidis, Enterococcus spp., Moraxella spp., streptococci viridans group, Escherichia coli, Serratia marcescens, Pseudomonas aeruginosa, and Proteus mirabilis have also been isolated less frequently from bacterial conjunctivitis samples.,30,31 Gram-positive pathogens accounted for $52.5 \%$ of positive cultures, $72.1 \%$ of which were $S$. aureus (Table 1). ${ }^{31}$ Staphylococci infections are more common in adults, while $S$. pneumoniae and $H$. influenzae are more common in children. ${ }^{31}$

Although clinical resolution of bacterial conjunctivitis occurs without any treatment in most patients by 7 days, treatment with broad-spectrum topical antibiotics accelerates the rate of clinical resolution and decreases the risk of contagious spread. ${ }^{4,15,30,32}$ Topical antibiotics indicated for bacterial conjunctivitis include aminoglycosides (eg, gentamicin and tobramycin), polymyxin-based combinations (eg, polymyxin B sulfate and trimethoprim), azithromycin, fluoroquinolones (eg, ciprofloxacin, levofloxacin, ofloxacin, moxifloxacin, and gatifloxacin), and, outside of the United States, chloramphenicol., ${ }^{40}$

\section{Bacterial keratitis}

Bacterial keratitis is a potentially devastating ocular infection that may occur when the corneal epithelial barrier is compromised due to injury or trauma, leading to ulceration and infiltration of inflammatory cells. ${ }^{33}$ Infection largely involves Gram-positive $S$. aureus, $S$. epidermidis, and several Streptococcus and Bacillus spp., as well as Gram-negative bacteria like $P$. aeruginosa, $S$. marcescens, Moraxella lacunata, Microbacterium liquefaciens, and $H$. influenzae. Immediate diagnosis and treatment are important to avoid vision-threatening outcomes, including corneal scarring or perforation. ${ }^{1}$ Clinical signs and symptoms include mild to severe ocular pain, photophobia, decreased vision, tearing, discharge, inflammation, focal white opacity in the corneal stroma (infiltrate), staining of the area (indicating an epithelial defect), corneal thinning, stromal edema, mild to severe anterior chamber reaction, and eyelid edema. ${ }^{7,8,34}$ The most common predisposing factors for bacterial keratitis are ocular trauma, contact lens wear (especially extended wear), ocular surface disease, and prior ocular surgery. ${ }^{7,34}$

Standard treatment of bacterial keratitis is a combination of cefazolin and tobramycin or an aminoglycoside such as gentamicin and a second-generation cephalosporin such as cefuroxime to avoid aminoglycoside retinal toxicity. ${ }^{11}$ Ciprofloxacin $0.3 \%$, ofloxacin $0.3 \%$, and levofloxacin $1.5 \%$ are indicated in the United States for the treatment of corneal ulcer, ${ }^{35-37}$ monotherapy with fluoroquinolones may now be the preferred treatment, especially if the infection is associated with wearing contact lenses. ${ }^{7}$ However, the emerging resistance of Gram-positive organisms to older agents and fluoroquinolones has underscored the importance of the clinical practice recommendation to culture all corneal ulcers before antimicrobial treatment. ${ }^{16}$ Newer fluoroquinolones are therefore recommended for initial therapy of bacterial

Table I Prevalence of most common isolates from patients with bacterial conjunctivitis recovered within the 2-year period ${ }^{31}$

\begin{tabular}{|c|c|c|c|c|c|c|}
\hline & | 994-|995 & |996-| 997 & |998-|999 & 2000-200I & 2002-2003 & Total \\
\hline Gram-positive & 166 (54.2\%) & $152(56.5 \%)$ & 128 (50.4\%) & $88(47.6 \%)$ & $12 \mathrm{I}(50.4 \%)$ & $655(52.5 \%)$ \\
\hline Staphylococcus aureus & $108(65.0 \%)$ & I 14 (75.0\%) & $89(69.5 \%)$ & $69(78.4 \%)$ & $92(76.0 \%)$ & $472(72.1 \%)$ \\
\hline Streptococcus pneumoniae & 18 (10.8\%) & 14 (9.2\%) & $21(16.4 \%)$ & II (I2.5\%) & 16 (13.2\%) & 80 (12.2\%) \\
\hline Streptococcus viridans group & 19 (1 I.6\%) & $6(3.9 \%)$ & $10(7.8 \%)$ & $6(6.8 \%)$ & $6(5.0 \%)$ & 47 (7.2\%) \\
\hline Gram-negative & | 40 (45.8\%) & II 7 (43.5\%) & 126 (49.6\%) & 97 (52.4\%) & 119 (49.6\%) & $599(47.8 \%)$ \\
\hline Haemophilus influenzae & $63(45.0 \%)$ & $53(45.3 \%)$ & $62(49.2 \%)$ & $50(51.5 \%)$ & $48(40.3 \%)$ & $276(46.1 \%)$ \\
\hline Pseudomonas aeruginosa & $16(11.4 \%)$ & $8(6.8 \%)$ & II (8.7\%) & $5(5.2 \%)$ & $17(14.3 \%)$ & $57(9.5 \%)$ \\
\hline Proteus mirabilis & 15 (I0.7\%) & $8(6.8 \%)$ & $8(6.3 \%)$ & $3(3.1 \%)$ & $7(5.9 \%)$ & $4 \mathrm{I}(6.8 \%)$ \\
\hline
\end{tabular}


keratitis to avoid progression of the ocular infection to corneal perforation, endophthalmitis, and even loss of the eye. ${ }^{33}$

\section{Endophthalmitis}

Endophthalmitis is a rare but potentially sight-threatening complication of intraocular surgery, intravitreal injections, and ocular trauma. ${ }^{9,38,39}$ The incidence of endophthalmitis following cataract surgery has increased over the last decade despite many technical advances and faster visual recovery, ${ }^{40}$ and ranges from $0.2 \%$ to $0.7 \%$ in the United States and Europe. ${ }^{10,41,42}$ The risk for occurrence of endophthalmitis following intravitreal injection of corticosteroids has been estimated to be $0.8 \%$ from noninfectious causes and $0.6 \%$ to $1.6 \%$ from infectious causes. ${ }^{37,43-46}$ Risk factors for endophthalmitis can be preoperative (blepharitis, lachrymal duct obstruction, contact lens use, and secondary intraocular lens implantation), intraoperative (inadequate eyelid or conjunctival disinfection, surgery lasting for more than 1 hour, loss of vitreous humor, or unplanned ocular penetration) or postoperative (wound abnormalities, inadequately buried sutures, suture removal, and vitreous incarceration in the surgical wound) ${ }^{47}$ Coagulase-negative Staphylococcus (CoNS) and Bacillus spp. are the most common pathogens of posttraumatic endophthalmitis. ${ }^{48}$ A postcataract study with 497 patients with endophthalmitis showed that more than $90 \%$ of the isolates were Gram-positive, mostly CoNS, and that the in vitro susceptibility profiles of these pathogens had changed over a decade. ${ }^{49} \mathrm{~A}$ review of 1182 consecutive open-globe injuries identified 10 patients with culture-proven endophthalmitis. Endophthalmitis-related isolates from these patients included Streptococcus spp. (46.2\%), CoNS (23.1\%), and Bacillus cereus (15.4\%). ${ }^{48}$

Intravitreal antibiotics including vancomycin and an aminoglycoside or third-generation cephalosporin are used to treat bacterial endophthalmitis, while vitrectomy may be needed for severe cases. ${ }^{9}$ Since the causal organisms of endophthalmitis may often be the patient's own conjunctival bacterial flora, many of the routinely used prophylactic measures aim to decrease the number of ocular bacteria before and after surgery. ${ }^{50,51}$ Prophylaxis for endophthalmitis includes ocular antibiotics and anti-inflammatory agents used in the pre-, peri-, and postoperative period, ${ }^{10,52}$ as well as intracameral use of cefuroxime at the end of surgery. ${ }^{53}$ Gatifloxacin and moxifloxacin are routinely administered topically along with the antiseptic povidone-iodine before cataract removal. ${ }^{11,52}$ Topical moxifloxacin was shown to reduce the incidence of endophthalmitis to less than $0.1 \%$ in a retrospective, observational case review of 20,013 patients, ${ }^{50}$ while intracameral use of cefuroxime at the end of surgery also reduced the occurrence of endophthalmitis to less than $0.1 \% .{ }^{53}$ More than $75 \%$ of ophthalmologists in the United States and Europe use preoperative antibiotics, among which the fluoroquinolones have grown increasingly popular. ${ }^{48,54,55}$ Neither topical antibiotics nor intracameral cefuroxime are indicated for endophthalmitis.

\section{Bacterial blepharitis}

Bacterial blepharitis is an infection and inflammation of the eyelid margin associated with hyperemia with crusting on the eyelashes. The most common complications of untreated blepharitis are abnormal eyelash growth (ie, trichiasis), scarring of the eyelids, and injury to the cornea due to constant irritation, which may cause small corneal ulcers. ${ }^{56}$ The most common causal pathogens for bacterial blepharitis are $S$. aureus and CoNS. ${ }^{56,57}$ The standard of care in bacterial blepharitis is antibiotic therapy along with lid scrubs and hot compresses. Ointments of erythromycin, bacitracin, or polymyxin have routinely been used. ${ }^{11}$ Antibiotic therapy in chronic bacterial blepharitis has to be optimized in order to avoid the development of antibiotic resistance due to long-term antibiotic use. ${ }^{11}$ In cases where ocular rosacea is a contributing factor to eyelid inflammation in bacterial blepharitis, oral tetracycline, doxycycline, or minocycline is also used. ${ }^{11}$

\section{Periorbital and orbital cellulitis}

Preseptal (periorbital) and postseptal (orbital) cellulitis are potentially vision-threatening bacterial infections of the periocular tissue. While preseptal cellulitis involves only the lid structures and periorbital tissues anterior to the orbital septum, postseptal cellulitis involves tissues behind the septum, and it is seen more commonly in children and adolescents than adults. Routes of infection include trauma, bacteremia, sinusitis, and upper respiratory infections. Signs and symptoms include swelling of the eye, pain, fever, erythema, impaired ocular motility, afferent pupillary defect, proptosis, and visual loss. Sinus radiographs, computed tomography, magnetic resonance imaging, and orbital ultrasonography are used for prognosis. The most common pathogen is H. influenzae. If there is an associated local wound, the pathogens may include $S$. aureus and Streptococcus pyogenes. ${ }^{58}$

Traditionally, azithromycin, cephalosporins, penicillins, and clindamycin have been used in oral form to provide broad-spectrum coverage against staphylococci, streptococci, and anaerobes associated with ocular sinusitis (nonviral) and orbital cellulitis. ${ }^{59}$ Alternatively, vancomycin or other 
intravenous antibiotics may be used.$^{58,59}$ Optic nerve function is monitored every 4 hours (through pupillary reactions, visual acuity, color vision, and light brightness appreciation). Treatment, which may be modified according to laboratory results, typically lasts 7 to 10 days. ${ }^{58}$ Surgery is indicated if there is a lack of response to antibiotic treatment or other complications occur. ${ }^{1}$

\section{Dacryocystitis}

Dacryocystitis is a painful inflammation of the lacrimal sac resulting from congenital or acquired obstruction of the nasolacrimal duct. In adults, it is idiopathic or the result of an obstruction from infection, trauma, or dacryolith, or rarely a neoplasm. ${ }^{60}$ In dacryocystitis, the medial lower lid location is protruding, tender, and painful, with discharge and tearing. The most common isolates in dacryocystitis are $P$. aeruginosa, S. aureus, Enterobacter aerogenes, Citrobacter, S. pneumoniae, E. coli, and Enterococcus spp. ${ }^{61,62}$ Treatment of dacryocystitis includes hot packs with topical and systemic antibiotics to cover penicillinaseproducing staphylococcal organisms. ${ }^{6}$ Clearing the drainage system, along with treatment with parenteral and topical antibiotics until the infection clears, is the standard therapy for dacryocystitis. ${ }^{1}$ Topical antibiotic treatment includes ceftazidime, ciprofloxacin, and cefuroxime. ${ }^{62} \mathrm{~A}$ higher incidence of Gram-negative organisms, particularly Pseudomonas, may indicate a trend in dacryocystitis infections towards antibiotic resistance. ${ }^{62}$ It is important to modify the antibiotic therapy based on a patient's response, laboratory culture, and sensitivity results to avoid the development of drug-resistant chronic dacryocystitis.

\section{Bacterial resistance in ocular infections}

The emerging resistance of ocular pathogens to topical antimicrobial agents is a worldwide problem. The emergence of bacterial resistance is influenced by characteristics of the pathogens, antibiotic-prescribing practices including the widespread use of systemic antibiotics, and health care guidelines. ${ }^{63}$ Data from the worldwide surveillance programs TRUST, GLOBAL, PROTEKT, ARM, SENTRY, ABC, and $\mathrm{TSN}^{64-69}$ document widespread resistance among the pathogens commonly responsible for systemic infections to many systemically administered antimicrobial agents. ${ }^{63,70,71}$ Worldwide, S. pneumoniae has a $20 \%$ to $30 \%$ resistance rate to penicillin and a $25 \%$ to $35 \%$ resistance rate to macrolides and azalides. ${ }^{72,73}$ In addition, $20 \%$ to $30 \%$ of $H$. influenzae isolates produce $\beta$-lactamase, which confers resistance to ampicillin. ${ }^{72,73}$ Ocular pathogen resistance to antimicrobial agents is increasing in parallel with an increase in antibiotic resistance in general, and is a major concern, since it narrows treatment choices for the management of common ocular infections. ${ }^{74}$ Surveillance studies that document resistance among ocular pathogens include Ocular TRUST ${ }^{25,26}$ and analyses of data from The Surveillance Network (TSN). ${ }^{27}$

\section{Increasing bacterial resistance in conjunctival infections}

Studies of bacterial isolates from ophthalmic infections have reported an increase in resistance to the older fluoroquinolone ciprofloxacin among $S$. aureus and the emergence of methicillin-resistant $S$. aureus (MRSA). ${ }^{26,65,74,75}$ A nearly 3 -fold increase in resistance to the older fluoroquinolones, including ciprofloxacin, among $S$. aureus isolates from conjunctival swabs was noted over a 10-year period (1994 to 2003), and the prevalence of MRSA among $S$. aureus isolates increased from $4.4 \%$ to $42.9 \%(P=0.001) .{ }^{31}$ Of note, a recent study of multidrug-resistant isolates (total of 1324 isolates examined) from clinical trials in bacterial conjunctivitis reported a significant prevalence of ciprofloxacin resistance in conjunction with methicillin resistance $-65 \%$ of MRSA isolates and $47 \%$ of methicillin-resistant $S$. epidermidis isolates were also ciprofloxacin resistant. ${ }^{76}$ Resistance has also increased to erythromycin and oxacillin among Grampositive isolates and to trimethoprim/sulfamethoxazole (TMP/SMX) among Gram-negative isolates. ${ }^{31}$ In a bacterial conjunctivitis study in pediatric patients $(\mathrm{N}=428$, ages 2 to 36 months), antibiotic resistance rates were high for pneumococcal isolates (penicillin, 60\%; TMP/SMX, 38\%; erythromycin, $23 \%$; tetracycline, $18 \%$; clindamycin, $9 \%$ ). ${ }^{77}$ Multidrug resistance was reported in $20 \%$ of pneumococcal isolates, highlighting the potential role of conjunctivitis in the spread of antibiotic-resistant pathogens. ${ }^{77}$

In a phase III study of resistance to azithromycin and moxifloxacin among conjunctival isolates, the $\mathrm{MIC}_{90}$ for tested organisms was below the CLSI-established resistance breakpoints for moxifloxacin and above the resistance breakpoints for azithromycin (3-fold higher for $H$. influenzae; $\geq 128$-fold higher for S. epidermidis; $\geq 16$-fold higher for $S$. pneumoniae; $\geq 128$-fold higher for $S$. aureus). ${ }^{78}$ In a killing kinetic study, moxifloxacin exhibited a faster speed of bacterial kill than other nonfluoroquinolone antibiotics (tobramycin, gentamicin, polymyxin B/trimethoprim, or azithromycin) in S. aureus, S. pneumoniae, and H. influenzae isolated from conjunctival swabs. ${ }^{79}$ These studies indicate that advanced-generation fluoroquinolones may kill bacteria more 
rapidly, leading to a faster resolution of ocular infection in the eye than with older topical ocular antibiotics and thereby reducing the risk of ocular drug resistance. ${ }^{79}$

The trend of growing ocular bacterial antibiotic resistance was also seen in a decrease in in vitro susceptibility to gentamicin and tobramycin in corneal and conjunctival samples. Susceptibility decreased among all tested pathogens from $88 \%$ to $95 \%$ at the beginning of the study to $50 \%$ to $80 \%$ at the end of the 15 -year surveillance period in $2000 .{ }^{80}$ Ninety percent of bacteria in the cornea and $95 \%$ of bacteria in the conjunctiva remained susceptible to ciprofloxacin, norfloxacin, and ofloxacin in $2000 .^{80} \mathrm{~A}$ subsequent 2-year Brazilian study ( $\mathrm{N}=219)$ also concluded that advanced-generation fluoroquinolones, such as gatifloxacin and moxifloxacin, were more active than older antibiotics against Gram-positive bacteria.$^{81}$ It is therefore important to treat bacterial conjunctivitis rapidly to decrease disease transmission, shorten symptom duration, and minimize the emergence and spread of resistant bacteria. ${ }^{79}$

\section{Increasing bacterial resistance in keratitis infections}

An increase in bacterial resistance has also been observed for keratitis infections. A review of resistance patterns over 2 consecutive 10-month periods found an increase in resistance rates among Gram-positive bacterial keratitis isolates to ciprofloxacin, cefazolin, and gentamicin. ${ }^{82}$ Increased resistance to these commonly used antibiotics indicated a need for close follow-up after initial treatment and suggested maintaining a low threshold for selecting alternative therapy. ${ }^{82}$ Among Gram-negative bacteria, a retrospective chart review of 1312 bacterial isolates from 1984 through 1999 found a significant $(P=0.0019)$ increase in chloramphenicol resistance, suggesting that chloramphenicol is unlikely to provide prophylactic coverage for Gram-negative ocular infections. ${ }^{83}$ In a study of 291 patients with presumed bacterial keratitis, $68 \%$ were culture positive, of which $83 \%$ of cultures were Gram-positive, 17\% Gram-negative, and $2 \%$ polymicrobial. ${ }^{6}$ In a 5-year retrospective review of patients $(\mathrm{N}=131)$ with bacterial keratitis, $P$. aeruginosa and $S$. aureus were the most common isolates, and $15.4 \%$ of $S$. aureus isolates were resistant to fluoroquinolones. ${ }^{33}$ Similar results were noted in another study in which, overall, 96.2\% of Gram-positive cocci isolated from bacterial keratitis samples $(\mathrm{N}=104)$ were susceptible to gatifloxacin, whereas $60.4 \%$ were susceptible to ciprofloxacin. ${ }^{84}$ No differences in susceptibility were observed among Gram-negative isolates. ${ }^{84}$ Corneal ulcer healing rates with gatifloxacin were significantly $(P<0.01)$ higher for infections caused by Gram-positive pathogens but not for those caused by Gram-negative pathogens, indicating that gatifloxacin may be a preferred (albeit off-label) alternative to ciprofloxacin as the first-line monotherapy in bacterial keratitis. ${ }^{84}$

As discussed earlier, higher concentrations of topical drugs are achievable in the eye; however, systemic minimum inhibitory concentration (MIC) values (CLSI standards) continue to be used as the susceptibility breakpoint in the treatment of ocular infections. The effect of MIC breakpoints on the rate of clinical response of bacterial keratitis isolates $(\mathrm{N}=663)$ to ciprofloxacin showed that for $\mathrm{MIC} \leq 1 \mu \mathrm{g} / \mathrm{mL}$, the cure rate was $74.5 \%(\mathrm{n}=272)$, but for isolates with MIC $\geq 1 \mu \mathrm{g} / \mathrm{mL}$, the cure rate was only $57.7 \%(n=15)$. This could indicate that ciprofloxacinresistant bacteria respond slowly to a higher concentration of ciprofloxacin, ${ }^{85}$ that organisms with higher MICs do not attain adequate pharmacodynamic goals for treatment, or that resistant mutants frequently emerge. Although this study may be limited by an inherent overestimation of the level of ciprofloxacin susceptibility on response rates, susceptibility testing of corneal cultures may predict the response of bacterial keratitis to fluoroquinolone therapy ${ }^{85}$

S. aureus isolated from bacterial keratitis samples $(\mathrm{N}=177)$ that was resistant to the older fluoroquinolones ciprofloxacin, levofloxacin, and ofloxacin remained susceptible to the advanced fluoroquinolones gatifloxacin and moxifloxacin. ${ }^{23}$ The $\mathrm{MIC}_{90}$ for the advanced-generation fluoroquinolones was lower than the $\mathrm{MIC}_{90}$ for the older agents for all other Gram-positive bacteria tested, indicating that the advanced fluoroquinolones exhibited greater potency against bacterial keratitis pathogens. Although ciprofloxacin still had the lowest $\mathrm{MIC}_{90}$ for Gram-negative bacteria, overall the newer fluoroquinolones offer significant advantages, especially for Gram-positive bacteria, in the treatment of bacterial keratitis. ${ }^{23}$ In one recent study, however, P. aeruginosa and S. aureus isolates from 2 cases of bacterial keratitis after refractive surgery showed resistance to moxifloxacin and gatifloxacin, highlighting the need to develop newer anti-infective agents. ${ }^{86}$

\section{Increasing bacterial resistance in endophthalmitis and other ocular infections}

Antimicrobial resistance, including to the advancedgeneration fluoroquinolones, has been identified from endophthalmitis isolates as well. The in vitro cross-resistance of gatifloxacin and moxifloxacin versus older fluoroquinolones 
was evaluated among 111 CoNS isolates recovered from patients with endophthalmitis over 15 years from January 1 , 1990, through December 31, 2004. ${ }^{87}$ More than $65 \%$ of the CoNS isolates resistant to ciprofloxacin $(n=38)$ also demonstrated in vitro cross-resistance to gatifloxacin $(65.8 \%)$ and moxifloxacin (71.1\%), indicating a significant increase in ocular pathogen resistance to fluoroquinolones over the 15 -year period ${ }^{87}$ Increasing in vitro resistance to gatifloxacin and moxifloxacin may have important implications for the prevention and treatment of postoperative endophthalmitis and reinforce the need to develop new fluoroquinolones. ${ }^{87}$

Overall, among bacterial isolates from ocular infections, MRSA strains increased from $29.5 \%$ in 2000 to $41.6 \%$ in 2005 (Figure 1). ${ }^{27}$ In this study of ocular isolates from more than 200 laboratories, fluoroquinolones were consistently active against methicillin-susceptible $S$. aureus (MSSA), $S$. pneumoniae, and $H$. influenzae but not against more than two-thirds of MRSA isolates. ${ }^{27}$ Moxifloxacin, gatifloxacin, levofloxacin, and ciprofloxacin were, respectively, effective against $92.1 \%, 90.2 \%, 90.6 \%$, and $91.1 \%$ of MSSA isolates, but only against $27.4 \%, 29.0 \%, 26.5 \%$, and $31.6 \%$ of MRSA isolates. ${ }^{25}$ In comparison, resistance among $P$. aeruginosa isolates was $10.5 \%$ to ciprofloxacin and gentamicin and $13.2 \%$ to gatifloxacin and ofloxacin. ${ }^{27}$

Similar trends were observed by the Ocular TRUST program, which evaluates the annual change of in vitro antimicrobial susceptibilities of $S$. pneumoniae, $H$. influen$z a e$, and $S$. aureus in national samples of ocular isolates. ${ }^{26}$
In this study, $17 \%$ of $S$. aureus isolates were methicillin resistant. About $75 \%$ to $85 \%$ of MRSA isolates were resistant to ciprofloxacin, levofloxacin, moxifloxacin, and gatifloxacin; $64 \%$ were resistant to tobramycin; and $91 \%$ were resistant to azithromycin. Increased in vitro MRSA resistance suggests the need to consider newer, more potent anti-infective agents when MRSA is a likely pathogen. ${ }^{26}$ The susceptibility rates of MSSA, S. pneumoniae, and H. influenzae to ciprofloxacin and levofloxacin varied from year to year, while the susceptibility patterns for the newer fluoroquinolones gatifloxacin and moxifloxacin in S. pneumoniae remained stable over the 8-year period studied (Figure 2). ${ }^{26}$ The Ocular TRUST 2 surveillance study reported that methicillin resistance in staphylococci was a marker for multidrug resistance. Susceptibility profiles for S. aureus, CoNS, S. pneumoniae, and H. influenzae to different ocular antibiotics also showed that newer fluoroquinolones were the most consistently active agents across the range of ocular pathogens. ${ }^{88}$ A European study of susceptibility to topical antimicrobial agents among 532 ocular pathogens found that overall resistance was substantially higher among MRSA isolates and lower among MSSA isolates as well (Table 2). ${ }^{89}$

As is evident from the studies discussed above, the increasing resistance of ocular pathogens to antibiotics has followed global increases in resistance to systemic antibiotics. ${ }^{71}$ These changes have important implications for the selection of antibiotic therapy for ocular infections. ${ }^{75}$ It is important to choose antibiotics with rapid bactericidal activity, based

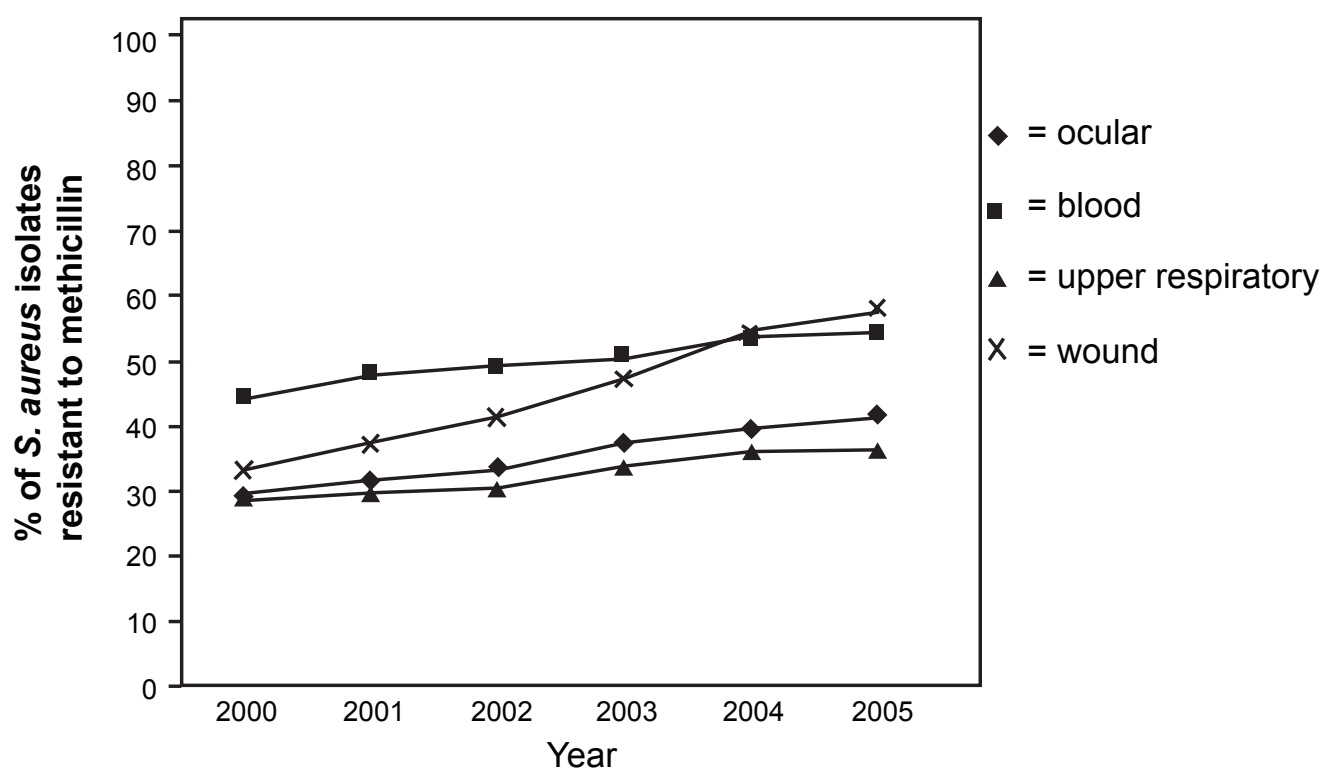

Figure I Percentage of S. aureus isolates resistant to methicillin (MRSA rate) according to specimen source (2000 to 2005 based on TSN database analysis). Reproduced with permission from Asbell PA, Sahm DF, Shaw M, Draghi DC, Brown NP. Increasing prevalence of methicillin resistance in serious ocular infections caused by Staphylococcus aureus in the United States: 2000 to 2005.J Cataract Refract Surg. 2008;34(5):814-818. ${ }^{27}$ Copyright (C 2008 Elsevier. 


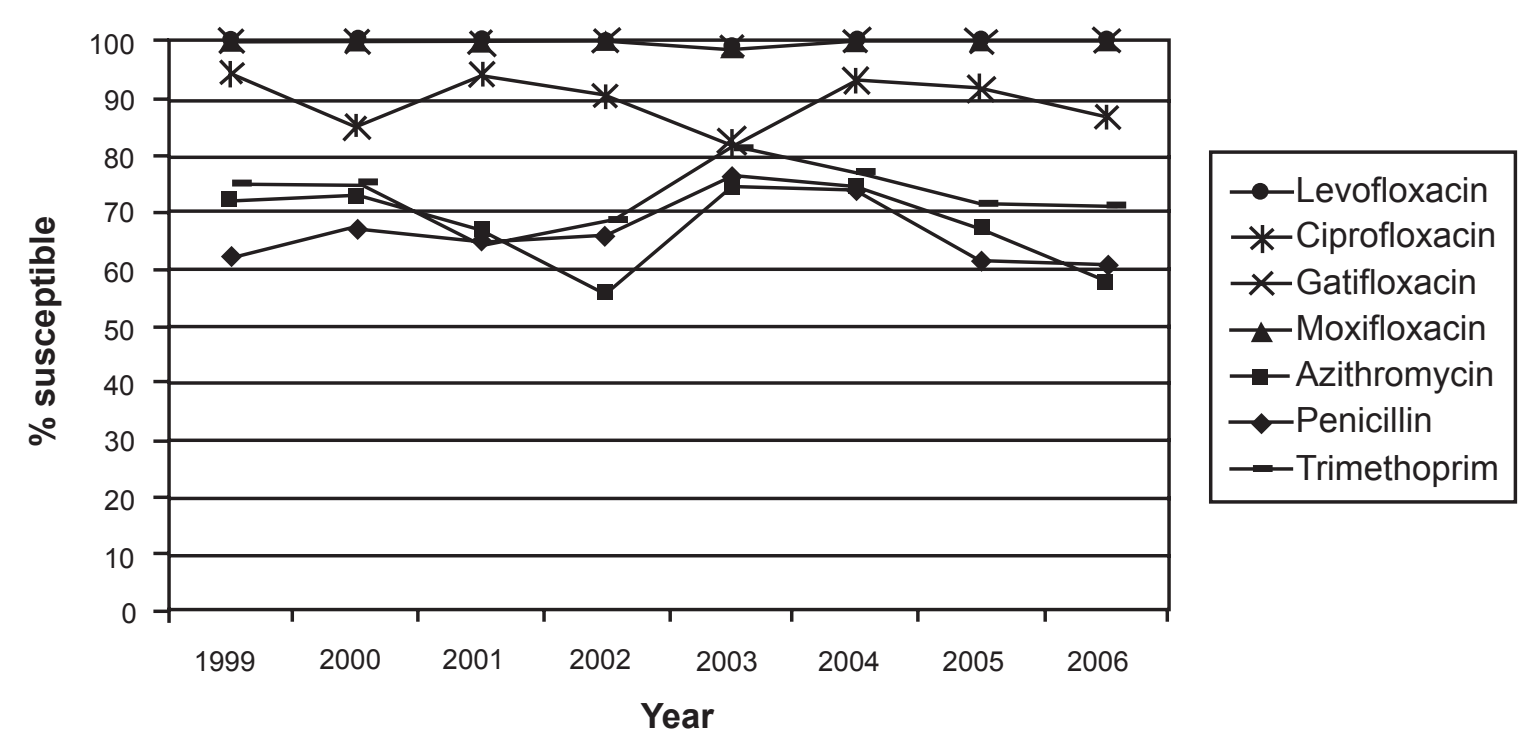

Figure 2 S. pneumoniae susceptibility in ocular isolates by drug from the Ocular Tracking Resistance in the U.S. Today (TRUST I) longitudinal surveillance program, I999 through 2006. Reproduced with permission from Asbell PA, Colby KA, Deng S, et al. Ocular TRUST: nationwide antimicrobial susceptibility patterns in ocular isolates. Am J Ophthalmol. 2008; I45(6):95I-958. ${ }^{26}$ Copyright (C) 2008 Elsevier.

on a combination of microbiology (low $\mathrm{MIC}_{90}$ values) and pharmacokinetic (PK) and pharmacodynamic (PD) data that predict killing of bacteria with limited development of pathogen resistance. The advanced-generation fluoroquinolones moxifloxacin and gatifloxacin have been efficacious for resolving ocular infections but have also been used systemically, increasing the chances of ocular pathogens having resistance to these agents. ${ }^{75,90-92}$ Although most of the new fluoroquinolones in development are being developed for systemic use, ideally newer agents should be specifically designed for topical ophthalmic use with an optimized combination of $\mathrm{PK}$ and reduced $\mathrm{MIC}_{90}$ (and thus optimized PD) versus MRSA isolates for increased efficacy and safety. ${ }^{27,90-92}$

Table 2 Ocular pathogen susceptibility to topical antimicrobial agents (not shown: 36 nonpneumoniae streptococci, 39 miscellaneous) ${ }^{89}$

\begin{tabular}{llllll}
\hline Organism (No of isolates) & \multicolumn{5}{l}{ Percentage of resistant pathogens } \\
\cline { 2 - 6 } & Gati & Cipro & Oflox & Gent & Chloram \\
\hline H. influenzae (83) & 0 & 0 & 0 & 0 & 1.2 \\
S. pneumoniae (70) & 0 & 1.4 & 0 & 94.3 & 7.1 \\
MSSA (123) & 0.8 & 2.4 & 1.6 & 1.6 & 1.6 \\
Enterobacteriaceae (60) & 3.4 & 5.1 & 5.1 & 8.5 & 18.6 \\
P. aeruginosa (38) & 13.2 & 10.5 & 13.2 & 10.5 & 100 \\
CoNS (48) & 2.1 & 31.3 & 31.3 & 18.8 & 20.8 \\
MRSA (35) & 57.1 & 91.4 & 91.4 & 37.1 & 2.9 \\
\hline
\end{tabular}

a532 ocular pathogens isolated from ocular infections from 200I to 2002. Abbreviations: Gati,gatifloxacin; Cipro, ciprofloxacin; Oflox, ofloxacin; Gent, gentamicin; Chloram, chloramphenicol; MSSA, methicillin-susceptible Staphylococcus aureus; CoNS, coagulase-negative Staphylococcus; MRSA, methicillin-resistant Staphylococcus aureus.
Breakpoints specific for topically administered ophthalmic antibiotics are needed to better understand resistance among ocular pathogens. ${ }^{90-92}$ Use of effective PD profiles of these new drugs to optimize antibiotic administration, maximize bactericidal effect, and minimize toxicity can lead to better clinical outcomes and prevention of bacterial resistance. ${ }^{93}$

\section{Importance of pharmacokinetics and pharmacodynamics in the development of new agents in ocular infection therapy}

Over the last decade, several lines of research have helped us understand the relevance of PD data in the development of new antibiotics for ocular infection. ${ }^{93}$ In preclinical studies, for a given organism, PD parameters provide a measurement for the rate and extent of bacterial kill and help to provide guidance on optimal modes of drug administration and reducing antibiotic resistance. ${ }^{93}$ A key measure for the optimization of an antibiotic's PD is the amount of time the free drug remains available at an exposure greater than the MIC ( $>$ MIC) for a pathogen, defined as the timedependent killing of the pathogen. Another measure for PD optimization of an antibiotic is the ratio of area under the free-drug concentration time curve (AUC) at 24 hours to the MIC (concentration-dependent killing) or AUC:MIC. ${ }^{94}$ The maximum concentration of the drug in target tissue after a dose $\left(\mathrm{C}_{\max }\right)$ compared to $\mathrm{MIC}\left(\mathrm{C}_{\max } / \mathrm{MIC}\right)$ is another parameter used to obtain the PD index. The relative importance 
of each of the PD parameters to a drug's antibacterial activity varies among antibiotics. ${ }^{94}$ For the fluoroquinolones, it has been estimated that a $\mathrm{C}_{\max }: \mathrm{MIC}_{90}$ ratio of at least 10 and an $\mathrm{AUC}: \mathrm{MIC}_{90}$ ratio of at least 100 are required to predict microbiological and clinical efficacy. ${ }^{95}$

The PD properties of an antibiotic vary by organism. A study of 7 fluoroquinolones compared the AUC:MIC ratio with an index based on the time needed after the removal of antibiotic for surviving bacteria to resume growth and reach $10^{9} \mathrm{CFU} / \mathrm{mL}$ bacterial culture growth density. ${ }^{96}$ The AUC:MIC ratio and the antimicrobial effect index $\left(\mathrm{I}_{\mathrm{E}}\right)$ were shown to be specific to each fluoroquinolone, with moxifloxacin and grepafloxacin having 1.4 times the antistaphylococcal effects of ciprofloxacin. ${ }^{96}$ When comparing therapeutically attainable total drug AUCs of fluoroquinolones in humans with the $\mathrm{I}_{\mathrm{E}}$ and the known ciprofloxacin susceptibility breakpoint, moxifloxacin, grepafloxacin, and trovafloxacin would require smaller AUC:MIC ratios to attain the same acceptable antistaphylococcal effect as ciprofloxacin, indicating greater potency of the newer fluoroquinolones. ${ }^{96}$

Optimal antibiotic PD may reduce the development of resistant mutants. Recent data with the fluoroquinolones suggest that a mutant-prevention concentration (MPC) may exist for certain organisms, such as S. pneumoniae. ${ }^{97}$ Although MPC has not been applied to other classes of antibiotics in general, the MPC for fluoroquinolones defines the antimicrobial drug concentration threshold that would require an organism to possess 2 mutations simultaneously for growth in the presence of the drug. ${ }^{29,98}$ Mutant prevention concentration and PD enable a clinician to optimize antimicrobial therapy by sustaining an antibiotic's ability to kill organisms while suppressing the emergence of resistant subpopulations of organisms. ${ }^{29,99,100}$

It is possible to extend the duration of antibiotic exposure for the ocular pathogen through the use of topical ocular antibiotics since these agents can achieve higher concentrations of the drug in the eye than systemic antibiotics. Factors that lead to high concentrations in the eye include the concentration of the formulation, its lipophilicity, and its aqueous solubility. ${ }^{101}$ To meet the need for differing ocular concentrations, ophthalmic antibiotics may be available in more than one formulation: for example, levofloxacin $0.5 \%$ and $1.5 \%$ for bacterial conjunctivitis and keratitis, respectively. ${ }^{37,102}$ However, topical formulations are often limited by formulation, such as solubility and stability, and by toxicity issues that could make it difficult to achieve increased efficacy through higher concentrations.
In light of the increasing antibiotic resistance pattern of bacteria worldwide, including resistance to the more potent, advanced-generation fluoroquinolones, the development of still newer, more potent fluoroquinolones and improvements in treatment protocols for ocular infections have become more important.

\section{A novel fluoroquinolone under investigation for the treatment of ocular infections}

Fluoroquinolones act by binding and inhibiting 2 enzymes involved in the synthesis of bacterial DNA - DNA gyrase and DNA topoisomerase IV - and are therefore considered to have a dual mechanism of action. ${ }^{103}$ Newer fluoroquinolones such as gatifloxacin and moxifloxacin have potent activity against both of these enzymes in both Gram-negative and Gram-positive organisms. In contrast, older fluoroquinolones, such as ofloxacin and ciprofloxacin, preferentially bind DNA gyrase in Gram-negative organisms and topoisomerase IV in Gram-positive organisms, leading to the potential for resistance to these agents following a single mutation in the target enzyme. ${ }^{103}$ In the newer fluoroquinolones, with strong affinities for both enzymes, double mutation of both target enzymes is needed for high-level resistance to develop. ${ }^{103}$

Besifloxacin (Besivance ${ }^{\mathrm{TM}}$; Bausch and Lomb Inc., Rochester, NY, USA), is a new fluoroquinolone that was recently approved by the US Food and Drug Administration for the treatment of bacterial conjunctivitis. This agent has a unique structure which may increase its potency. ${ }^{104}$ Besifloxacin ophthalmic suspension $0.6 \%$ has been developed exclusively for the treatment of ocular infections, reducing the risk of the emergence of resistant strains due to prior widespread systemic exposure to that agent. ${ }^{104}$ Besifloxacin's mechanism of action is similar to that of other fluoroquinolones in that it kills bacteria through inhibition of DNA gyrase and topoisomerase IV. ${ }^{105}$ Unlike older representatives of that drug family, besifloxacin has balanced dual activity, inhibiting both enzymes at similar as well as lower concentrations. Thus, the inhibition of the enzymatic activities of DNA gyrase and topoisomerase IV of $S$. pneumoniae occurs at lower concentrations with besifloxacin than with ciprofloxacin, and even with moxifloxacin. ${ }^{105}$ Since both enzymes are targeted simultaneously, mutations leading to high-level resistance to besifloxacin cannot occur in a single step. While mutations that increased the MIC values for besifloxacin 
were found in laboratory strains of E. coli, S. aureus, and $S$. pneumoniae, the increase in MIC was far greater for the comparators ciprofloxacin and moxifloxacin. ${ }^{105}$ Besifloxacin has been shown to be active in vitro against a broad spectrum of pathogens, including the most common pathogens of bacterial conjunctivitis as well as drugresistant isolates (Table 3). ${ }^{76,106}$

Besifloxacin demonstrated efficacy in an in vivo murine infection model and excellent ocular pharmacokinetics in rabbits, with ocular mean residence times of $>7$ hours and conjunctival concentrations in excess of the $\mathrm{MIC}_{90}$ for nonresistant ophthalmic isolates for $>12$ hours following a single dose. ${ }^{104}$ Single doses of besifloxacin administered to rabbit eyes maintained high concentrations in tears, conjunctiva, and aqueous humor, with mean residence times of 923 , 458, and 422 minutes, respectively. ${ }^{104,107}$ Compared with gatifloxacin and moxifloxacin, besifloxacin demonstrated greater exposure in tears and conjunctiva with lower systemic concentrations. ${ }^{108}$ The conjunctival $\mathrm{C}_{\max }: \mathrm{MIC}_{90}$ ratio for besifloxacin exceeds 10 for all 8 nonresistant species, and the AUC: $\mathrm{MIC}_{90}$ ratio exceeds 100 for all species except P. aeruginosa. ${ }^{104}$ Based on a conjunctival besifloxacin $\mathrm{C}_{\max }$ of $63 \mu \mathrm{g} / \mathrm{mL}$ and a predicted (from PK modeling and simulations) $\mathrm{AUC}_{(0-24 \mathrm{~h})}$ of $214 \mu \mathrm{g} \cdot \mathrm{h} / \mathrm{mL}, 3$ times per day (tid) dosing of besifloxacin $0.6 \%$ for 1 week should attain adequate therapeutic AUC: $\mathrm{MIC}_{90}$ ratios and prevent the development of 2-step resistant mutants. ${ }^{104}$

In a rabbit model of MRSA-induced endophthalmitis, besifloxacin treatment resulted in significant improvement in clinical score (reductions in the signs and symptoms of endophthalmitis), while gatifloxacin, levofloxacin, and moxifloxacin were ineffective. ${ }^{109}$ Besifloxacin also exhibited significant dose-dependent inhibition of IL-1 $\beta$ or lipopolysaccharidestimulated cytokines in human monocytes, with a comparable or better potency than moxifloxacin, indicating that besifloxacin may have anti-inflammatory activity. ${ }^{110}$ Similarly, besifloxacin significantly inhibited IL-1ß-induced release of proinflammatory cytokines in primary human corneal epithelial cells in a dose-dependent manner, with a comparable or better efficacy compared to moxifloxacin. ${ }^{109}$

Table 3 MIC $_{90}$ values for besifloxacin against common causes of bacterial conjunctivitis ${ }^{76,106}$

\begin{tabular}{|c|c|c|}
\hline Bacterial strain & Besifloxacin: MIC $_{90}$ & Comparator(s): MIC $_{90}$ \\
\hline Susceptible S. aureus ${ }^{a}$ & $0.03-0.5 \mu \mathrm{g} / \mathrm{mL}$ & N/A \\
\hline Susceptible S. epidermidis ${ }^{a}$ & $0.03-0.5 \mu g / \mathrm{mL}$ & $N / A$ \\
\hline Susceptible S. pneumoniae ${ }^{a}$ & $0.03-0.5 \mu \mathrm{g} / \mathrm{mL}$ & $\mathrm{N} / \mathrm{A}$ \\
\hline Susceptible $H$. influenzae ${ }^{a}$ & $0.03-0.5 \mu \mathrm{g} / \mathrm{mL}$ & $\mathrm{N} / \mathrm{A}$ \\
\hline MRSA & $0.06 \mu g / \mathrm{mL}$ & N/A \\
\hline Vancomycin-intermediate S. aureus & $2 \mu \mathrm{g} / \mathrm{mL}$ & N/A \\
\hline Methicillin/ciprofloxacin-resistant S. aureus & $8 \mu \mathrm{g} / \mathrm{mL}$ & $\mathrm{N} / \mathrm{A}$ \\
\hline Penicillin-resistant S. pneumoniae & $0.12 \mu \mathrm{g} / \mathrm{mL}$ & N/A \\
\hline Levofloxacin-resistant S. pneumoniae & $2 \mu \mathrm{g} / \mathrm{mL}$ & $\mathrm{N} / \mathrm{A}$ \\
\hline H. influenzae with $\beta$-lactamase production & $0.03 \mu g / \mathrm{mL}$ & N/A \\
\hline$\beta$-lactamase-positive, ampicillin-resistant $H$. influenzae & $0.12 \mu \mathrm{g} / \mathrm{mL}$ & N/A \\
\hline Ciprofloxacin-susceptible MSSA & $0.06 \mu \mathrm{g} / \mathrm{mL}$ & $\begin{array}{l}\text { Moxifloxacin: } 0.125 \mu \mathrm{g} / \mathrm{mL} \\
\text { Gatifloxacin: } 0.25 \mu \mathrm{g} / \mathrm{mL}\end{array}$ \\
\hline Ciprofloxacin-resistant MSSA & $2 \mu \mathrm{g} / \mathrm{mL}$ & $\begin{array}{l}\text { Moxifloxacin: } 8 \mu \mathrm{g} / \mathrm{mL} \\
\text { Gatifloxacin: }>8 \mu \mathrm{g} / \mathrm{mL}\end{array}$ \\
\hline Methicillin-susceptible S. epidermidis sensitive to ciprofloxacin & $0.06 \mu g / \mathrm{mL}$ & $\begin{array}{l}\text { Moxifloxacin: } 0.125 \mu \mathrm{g} / \mathrm{mL} \\
\text { Gatifloxacin: } 0.25 \mu \mathrm{g} / \mathrm{mL}\end{array}$ \\
\hline Methicillin-resistant S. epidermidis sensitive to ciprofloxacin & $0.06 \mu g / \mathrm{mL}$ & $\begin{array}{l}\text { Moxifloxacin: } 0.125 \mu \mathrm{g} / \mathrm{mL} \\
\text { Gatifloxacin: } 0.25 \mu \mathrm{g} / \mathrm{mL}\end{array}$ \\
\hline S. aureus parC S80Y + gyrA S84L double mutant & $0.5 \mu \mathrm{g} / \mathrm{mL}$ & $\begin{array}{l}\text { Moxifloxacin: } 0.5 \mu \mathrm{g} / \mathrm{mL} \\
\text { Ciprofloxacin: } 32 \mu \mathrm{g} / \mathrm{mL}\end{array}$ \\
\hline S. pneumoniae parC S79Y + gyrA S8IY double mutant & $\mathrm{I} \mu \mathrm{g} / \mathrm{mL}$ & $\begin{array}{l}\text { Moxifloxacin: } 4 \mu \mathrm{g} / \mathrm{mL} \\
\text { Ciprofloxacin: } 64 \mu \mathrm{g} / \mathrm{mL}\end{array}$ \\
\hline
\end{tabular}

anpublished data Bausch \& Lomb Inc.

Abbreviations: MRSA, methicillin-resistant Staphylococcus aureus; MSSA, methicillin-susceptible Staphylococcus aureus. 
Although the clinical significance of anti-inflammatory activity has not been established, reducing inflammation associated with infections may enhance drug access to ocular tissue and reduce tissue damage. ${ }^{109,110}$

Human subjects $(\mathrm{N}=64)$ administered a single-dose of besifloxacin ophthalmic suspension $0.6 \%$ in both eyes had mean tear AUC:MIC ratios (24 hours) ranging from 2464 to 20,533 for S. aureus, S. pneumoniae, S. epidermidis, and $H$. influenzae. ${ }^{111}$ On average, besifloxacin concentrations of $1.6 \mu \mathrm{g} / \mathrm{g}$ or higher were sustained in tears for at least 24 hours after a single dose. ${ }^{112}$ These values are greater than the $\mathrm{MIC}_{90}$ values for the common ocular pathogens and are above the exposure needed to eradicate the organism and prevent the development of resistant mutants. ${ }^{111}$ The PD data presented here are therefore indicative of a prolonged and effective ocular concentration of the drug. The high AUC:MIC ratio over 24 hours reported in this study suggests that the extended-release mucoadhesive polymer (DuraSite ${ }^{\circledR}$; Insite Vision, Alameda, CA, USA) used for the besifloxacin ophthalmic suspension formulation is an optimal choice for the treatment of ocular infections. In this context, formulations such as in situ gelling ophthalmic delivery systems have also been reported to provide increased bioavailability for fluoroquinolones such as gatifloxacin, ciprofloxacin, and ofloxacin although it is not clear if or when these products may become available in the future. ${ }^{113-115}$

The efficacy and safety of besifloxacin ophthalmic suspension $0.6 \%$ was studied in two multicenter, randomized, double-masked, vehicle-controlled, parallel-design trials with patient populations of 269 and 957. In both trials, the efficacy and safety of besifloxacin ophthalmic suspension $0.6 \%$ tid for 5 days was compared with vehicle for the complete clinical resolution and eradication of bacterial infection. ${ }^{16,117}$ In the first trial, clinical resolution at the primary analysis visit (Day 8) occurred in 73.3\% (44/60) of besifloxacin-treated patients with culture-confirmed conjunctivitis versus $43.1 \%(25 / 58)$ of patients receiving vehicle $(P<0.001) .{ }^{116}$ Bacterial eradication occurred in $88.3 \%(53 / 60)$ of patients in the besifloxacin group versus $60.3 \%(35 / 58)$ of vehicle-treated patients $(P<0.001) .{ }^{116}$ In the second trial, clinical resolution at the primary analysis visit (Day 5) occurred in 45.2\% (90/199) of besifloxacintreated patients with culture-confirmed conjunctivitis versus $33.0 \%(63 / 191)$ of patients receiving vehicle $(P=0.0084)$, while bacterial eradication occurred in $91.5 \%(182 / 199)$ of patients in the besifloxacin group versus 59.7\% (114/191) of vehicle-treated patients $(P<0.0001) .{ }^{117}$ In the first trial, the cumulative frequency of ocular adverse events (AEs) was similar between the 2 groups ${ }^{116}$; however, in the second trial, the cumulative frequency of ocular AEs was statistically greater in the vehicle treatment group $(P=0.0047)$, due, in part, to the higher incidence of conjunctivitis in the vehicletreated group. ${ }^{117}$

A non-inferiority study compared the efficacy and safety of besifloxacin and moxifloxacin $0.5 \%$ tid for 5 days for the treatment of bacterial conjunctivitis $(\mathrm{N}=1161,533$ of whom had positive cultures). ${ }^{118}$ Clinical resolution at the primary analysis visit (Day 5) occurred in 58.3\% and 59.4\% of patients (besifloxacin and moxifloxacin, respectively; $P=0.652$; CI, $-9.48 \%$ to $7.29 \%$ ), and bacterial eradication occurred in $93.3 \%$ and $91.1 \%$ (besifloxacin and moxifloxacin, respectively; $P=0.1238$; $\mathrm{CI},-2.44 \%$ to $6.74 \%$ ), indicating that besifloxacin was non-inferior to moxifloxacin for the treatment of bacterial conjunctivitis. ${ }^{118}$ Besifloxacin was well tolerated, with an incidence of AEs that was similar to that reported for vehicle or moxifloxacin with no unexpected findings. ${ }^{118}$ Eye irritation was the only ocular AE statistically different between treatment groups, occurring in $0.3 \%$ of subjects on besifloxacin and $1.4 \%$ of subjects on moxifloxacin $(P=0.0201)$. The only nonocular AE that occurred in more than $1 \%$ was headache $(1.2 \%$ besifloxacin, $1.6 \%$ moxifloxacin). ${ }^{118}$

\section{Strategies for prevention of antibiotic resistance in ocular pathogens}

The Centers for Disease Control and Prevention and the World Health Organization have proposed strategies to preserve the usefulness of antibiotics. ${ }^{119,120}$ In addition to global surveillance programs, adequate training and awareness programs should be implemented. ${ }^{19,120}$ However, surveillance programs must be evaluated with reference to the PD data that influence the concentration of an antibiotic in the eye. Ocular TRUST data show that ciprofloxacin resistance has increased over the past decade. ${ }^{26}$ The improved PD properties of the newer generation fluoroquinolones help to maximize the concentration of the antibiotic at the site of infection and help to reduce the incidence of bacterial resistance. Strategies to prevent or delay the development of antibiotic resistance among ocular pathogens include the prescription of antibiotics only when needed and the use of sensitivity testing to prescribe the appropriate antibiotic. ${ }^{75}$ Additional recommended strategies for the prevention of antibiotic resistance are completion of the full course of therapy and the decrease in the use of antibiotics for growth promotion in animals and agriculture, as well as the development 
of new antibiotic agents with optimized PD. ${ }^{121}$ Ultimate outcomes of treatment depend on efficacy and safety of the pharmacotherapy as well as adherence to the established guidelines. Prevention of ocular antibiotic resistance requires cooperation between patients, physicians (both eye care and non-eye care), and the pharmaceutical industry to keep current antibiotics effective for a longer time and to develop newer antibiotic agents to stay ahead of the changing microbial pathogenesis.

\section{Conclusion}

Evolving bacterial resistance represents a worldwide challenge in the clinical management of infection. A parallel increase in resistance among ocular pathogens has necessitated transitioning from older to newer, more potent antibiotics. In the future, antibiotics for ocular infections should possess a broad spectrum of activity against a wide range of pathogens and be effective and safe to use at the optimized $\mathrm{PK} / \mathrm{PD}$ and $\mathrm{MIC}_{90}$ against resistant strains of bacteria. ${ }^{22}$ Currently, the newer fluoroquinolones gatifloxacin and moxifloxacin, and in the near future besifloxacin, appear to represent the best choice for treating and preventing ophthalmic infections. Agents developed specifically for ocular use only may help to overcome the evolving global antibiotic resistance problem that has resulted from inappropriate widespread use of systemic antibiotics.

\section{Acknowledgments and Disclosures}

The author wishes to thank Richard S Perry, PharmD, of Churchill Communications and Richa Attre, PhD, of The Scienomics Group for writing and editorial assistance. The author declares no conflicts of interest.

\section{References}

1. Snyder R, Glasser D. Antibiotic therapy for ocular infection. West $J$ Med. 1994;161(6):579-584.

2. Hughes L, Maurice D. A fresh look at iontophoresis. Arch Ophthalmol. 1984;102(12):1825-1829.

3. Hovding G. Acute bacterial conjunctivitis. Acta Ophthalmol. 2008; 86(1):5-17.

4. Rose P. Management strategies for acute infective conjunctivitis in primary care: a systematic review. Expert Opin Pharmacother. 2007;8(12):1903-1921.

5. Allan BD, Dart JK. Strategies for the management of microbial keratitis. Br J Ophthalmol. 1995;79(8):777-786.

6. Bourcier T, Thomas F, Borderie V, Chaumeil C, Laroche L. Bacterial keratitis: predisposing factors, clinical and microbiological review of 300 cases. Br J Ophthalmol. 2003;87(7):834-838.

7. Green M, Apel A, Stapleton F. Risk factors and causative organisms in microbial keratitis. Cornea. 2008;27(1):22-27.

8. Green MD, Apel AJ, Naduvilath T, Stapleton FJ. Clinical outcomes of keratitis. Clin Experiment Ophthalmol. 2007;35(5): $421-426$.
9. Callegan MC, Gilmore MS, Gregory M, et al. Bacterial endophthalmitis: therapeutic challenges and host-pathogen interactions. Prog Retin Eye Res. 2007;26(2):189-203.

10. DeCroos FC, Afshari NA. Perioperative antibiotics and antiinflammatory agents in cataract surgery. Curr Opin Ophthalmol. 2008;19(1):22-26.

11. Kowalski RP, Dhaliwal DK. Ocular bacterial infections: current and future treatment options. Expert Rev Anti Infect Ther. 2005;3(1):131-139.

12. Tovilla-Canales JL, Nava A, Tovilla y Pomar JL. Orbital and periorbital infections. Curr Opin Ophthalmol. 2001;12(5):335-341.

13. Campolattaro BN, Lueder GT, Tychsen L. Spectrum of pediatric dacryocystitis: medical and surgical management of 54 cases. J Pediatr Ophthalmol Strabismus. 1997;34(3):143-153.

14. Summary benchmarks for preferred practice pattern guidelines. San Francisco, CA: American Academy of Ophthalmology; 2007.

15. American Academy of Ophthalmology Cornea and External Disease Panel. Preferred practice pattern: conjunctivitis. San Francisco, CA: American Academy of Ophthalmology; 2003.

16. American Academy of Ophthalmology Cornea and External Disease Panel. Preferred practice pattern: bacterial keratitis. San Francisco, CA: American Academy of Ophthalmology; 2005.

17. Dart JK, Radford CF, Minassian D, Verma S, Stapleton F. Risk factors for microbial keratitis with contemporary contact lenses: a case-control study. Ophthalmology. 2008;115(10):1647-1654.

18. Donahue SP, Khoury JM, Kowalski RP. Common ocular infections. A prescriber's guide. Drugs. 1996;52(4):526-540.

19. Bartlett JD. Ophthalmic Drug Facts. 20th ed. St. Louis, MO: Wolters Kluwer Health; 2009.

20. Mulligan MJ, Cobbs CG. Bacteriostatic versus bactericidal activity. Infect Dis Clin North Am. 1989;3(3):389-398.

21. Fraunfelder F. Corneal toxicity from topical ocular and systemic medications. Cornea. 2006;25(10):1133-1138.

22. Schlech BA, Blondeau J. Future of ophthalmic anti-infective therapy and the role of moxifloxacin ophthalmic solution $0.5 \%$ (VIGAMOX). Surv Ophthalmol. 2005;50(Supp1 1):S64-S67.

23. Kowalski RP, Dhaliwal DK, Karenchak LM, et al. Gatifloxacin and moxifloxacin: an in vitro susceptibility comparison to levofloxacin, ciprofloxacin, and ofloxacin using bacterial keratitis isolates. Am J Ophthalmol. 2003;136(3):500-505.

24. Stratton CW. Dead bugs don't mutate: susceptibility issues in the emergence of bacterial resistance. Emerg Infect Dis. 2003;9(1):10-16.

25. Asbell PA, Sahm DF. Nationwide antimicrobial susceptibility surveillance of ocular isolates: results of Ocular TRUST. Presented at the American Society of Cataract and Refractive Surgery Annual Meeting; 2007 Apr 22-May 2; San Diego, CA. Abstract \#P-114.

26. Asbell PA, Colby KA, Deng S, et al. Ocular TRUST: nationwide antimicrobial susceptibility patterns in ocular isolates. Am J Ophthalmol. 2008;145(6):951-958.

27. Asbell PA, Sahm DF, Shaw M, Draghi DC, Brown NP. Increasing prevalence of methicillin resistance in serious ocular infections caused by Staphylococcus aureus in the United States: 2000 to 2005. J Cataract Refract Surg. 2008;34(5):814-818.

28. Hwang DG. The top four errors in prescribing antibiotics. Cataract Refract Surg Today. Feb. 2005:55-58.

29. Blondeau JM, Hansen G, Metzler K, Hedlin P. The role of PK/PD parameters to avoid selection and increase of resistance: mutant prevention concentration. J Chemother. 2004;16(Suppl 3):1-19.

30. Bartlett JD, Jaanus S. Clinical Ocular Pharmacology. St. Louis, MO: Butterworth Heinemann Elsevier; 2008.

31. Cavuoto K, Zutshi D, Karp CL, Miller D, Feuer W. Update on bacterial conjunctivitis in South Florida. Ophthalmology. 2008;115(1): $51-56$.

32. Sheikh A, Hurwitz B. Antibiotics versus placebo for acute bacterial conjunctivitis. Cochrane Database Syst Rev. 2006;(2):CD001211.

33. Pachigolla G, Blomquist P, Cavanagh HD. Microbial keratitis pathogens and antibiotic susceptibilities: a 5-year review of cases at an urban county hospital in north Texas. Eye Contact Lens. 2007;33(1):45-49. 
34. Keay L, Edwards K, Naduvilath T, et al. Microbial keratitis predisposing factors and morbidity. Ophthalmology. 2006;113(1):109-116.

35. Ciloxan [package insert]. Fort Worth, TX; Alcon Laboratories, Inc; March 1998.

36. Ocuflox [package insert]. Irvine, CA; Allergan Inc; July 1993.

37. Iquix [package insert] Jacksonville, FL; Vistakon Pharmaceuticals LLC; April 2007.

38. Bhavsar AR, Ip MS, Glassman AR. The risk of endophthalmitis following intravitreal triamcinolone injection in the DRCRnet and SCORE clinical trials. Am J Ophthalmol. 2007;144(3):454-456.

39. Jonas JB. Intravitreal triamcinolone acetonide: a change in a paradigm. Ophthalmic Res. 2006;38(4):218-245.

40. Taban M, Behrens A, Newcomb R, et al. Acute endophthalmitis following cataract surgery: a systematic review of the literature. Arch Ophthalmol. 2005;123(5):613-620.

41. West ES, Behrens A, McDonnell PJ, Tielsch JM, Schein OD. The incidence of endophthalmitis after cataract surgery among the US Medicare population increased between 1994 and 2001. Ophthalmology. 2005;112(8):1388-1394.

42. Johnson M, Doft B, Kelsey S, et al. The Endophthalmitis Vitrectomy Study: relationship between clinical presentation and microbiologic spectrum. Ophthalmology. 1997;104(2):261-272.

43. Jager R, Aiello L, Patel S, Cunningham EJ. Risks of intravitreous injection: a comprehensive review. Retina. 2004;24(5):676-698.

44. Jonas JB, Kreissig I, Spandau UH, Harder B. Infectious and noninfectious endophthalmitis after intravitreal high-dosage triamcinolone acetonide. Am J Ophthalmol. 2006;141(3):579-580.

45. Jonas JB, Spandau UH, Rensch F, Von Baltz S, Schlichtenbrede F. Infectious and noninfectious endophthalmitis after intravitreal bevacizumab. J Ocul Pharmacol Ther. 2007;23(3):240-242.

46. Jonas JB, Spandau UH, Schlichtenbrede F. Short-term complications of intravitreal injections of triamcinolone and bevacizumab. Eye. 2008;22(4):590-591

47. Yam JC, Kwok AK. Update of the management of postoperative endophthalmitis. Hong Kong Med J. 2004;10(5):337-343.

48. Chhabra S, Kunimoto DY, Kazi L, et al. Endophthalmitis after open globe injury: microbiologic spectrum and susceptibilities of isolates. Am J Ophthalmol. 2006;142(5):852-854.

49. Recchia FM, Busbee BG, Pearlman RB, Carvalho-Recchia CA, Ho AC. Changing trends in the microbiologic aspects of postcataract endophthalmitis. Arch Ophthalmol. 2005;123(3):341-346.

50. Moshirfar M, Feiz V, Vitale AT, Wegelin JA, Basavanthappa S, Wolsey DH. Endophthalmitis after uncomplicated cataract surgery with the use of fourth-generation fluoroquinolones: a retrospective observational case series. Ophthalmology. 2007;114(4):686-691.

51. Olson R. Reducing the risk of postoperative endophthalmitis. Surv Ophthalmol. 2004;49(Suppl 2):S55-S61.

52. Kelkar A, Kelkar J, Amuaku W, Kelkar U, Shaikh A. How to prevent endophthalmitis in cataract surgeries. Indian J Ophthalmol. 2008;56(5):403-407.

53. Endophthalmitis Study Group, European Society of Cataract and Refractive Surgeons. Prophylaxis of postoperative endophthalmitis following cataract surgery: results of the ESCRS multicenter study and identification of risk factors. J Cataract Refract Surg. 2007;33(6):978-988.

54. Masket S. Preventing, diagnosing, and treating endophthalmitis. J Cataract Refract Surg. 1998;24(6):725-726.

55. Schmitz S, Dick H, Krummenauer F, Pfeiffer N. Endophthalmitis in cataract surgery: results of a German survey. Ophthalmology. 1999; 106(10):1869-1877.

56. Jackson W. Blepharitis: current strategies for diagnosis and management. Can J Ophthalmol. 2008;43(2):170-179.

57. Groden L, Murphy B, Rodnite J, et al. Lid flora in blepharitis. Cornea. 1991;10:50-53.

58. Rutar T, Zwick OM, Cockerham KP, Horton JC. Bilateral blindness from orbital cellulitis caused by community-acquired methicillinresistant Staphylococcus aureus. Am J Ophthalmol. 2005;140(4): $740-742$.
59. Cannon P, Keag D, Radford R, Ataullah S, Leatherbarrow B. Our experience using primary oral antibiotics in the management of orbital cellulitis in a tertiary referral centre. Eye. 2009;23(3):612-615.

60. Das J, Deka A, Kuri G, Bhattacharjee K, Das D, Gogoi K. Bacteriology of chronic dacryocystitis in adult population of northeast India. Orbit. 2008;27(4):243-247.

61. Kubal A, Garibaldi D. Dacryoadenitis caused by methicillinresistant Staphylococcus aureus. Ophthal Plast Reconstr Surg. 2008;24(1):50-61.

62. Briscoe D, Rubowitz A, Assia E. Changing bacterial isolates and antibiotic sensitivities of purulent dacryocystitis. Orbit. 2005;24(2):95-98.

63. Harbarth S, Samore MH. Antimicrobial resistance determinants and future control. Emerg Infect Dis. 2005;11(6):794-801.

64. Gums JG, Boatwright DW, Totti N, Martinez M. Antimicrobial resistance in 11 hospitals in Puerto Rico: results of an antimicrobial resistance management (ARM) program. P R Health Sci J. 2007;26(3): 181-189.

65. Goldstein MH, Kowalski RP, Gordon YJ. Emerging fluoroquinolone resistance in bacterial keratitis: a 5-year review. Ophthalmology. 1999; 106(7):1313-1318.

66. Miliani K, L'Heriteau F, Alfandari S, et al. Specific control measures for antibiotic prescription are related to lower consumption in hospitals: results from a French multicentre pilot study. J Antimicrob Chemother. 2008;62(4):823-829.

67. Hoban D, Felmingham D. The PROTEKT surveillance study: antimicrobial susceptibility of Haemophilus influenzae and Moraxella catarrhalis from community-acquired respiratory tract infections. J Antimicrob Chemother. 2002;50(Suppl S1):49-59.

68. Kirby JT, Mutnick AH, Jones RN, Biedenbach DJ, Pfaller MA. Geographic variations in garenoxacin (BMS284756) activity tested against pathogens associated with skin and soft tissue infections: report from the SENTRY Antimicrobial Surveillance Program (2000). Diagn Microbiol Infect Dis. 2002;43(4):303-309.

69. Tenover FC. Mechanisms of antimicrobial resistance in bacteria. Am J Med. 2006;119(6 Suppl 1):S3-S10; discussion S62-S70.

70. Barlow G, Nathwani D. Is antibiotic resistance a problem? A practical guide for hospital clinicians. Postgrad Med J. 2005;81(961): 680-692.

71. Croft AC, D'Antoni AV, Terzulli SL. Update on the antibacterial resistance crisis. Med Sci Monit. 2007;13(6):RA103-RA118.

72. Brown SD, Rybak MJ. Antimicrobial susceptibility of Streptococcus pneumoniae, Streptococcus pyogenes and Haemophilus influenzae collected from patients across the USA, in 2001-2002, as part of the PROTEKT US study. J Antimicrob Chemother. 2004;54(Suppl 1): i7-i15.

73. Jacobs MR, Felmingham D, Appelbaum PC, Gruneberg RN. The Alexander Project 1998-2000: susceptibility of pathogens isolated from community-acquired respiratory tract infection to commonly used antimicrobial agents. J Antimicrob Chemother. 2003;52(2): 229-246.

74. Marangon FB, Miller D, Muallem MS, Romano AC, Alfonso EC. Ciprofloxacin and levofloxacin resistance among methicillin-sensitive Staphylococcus aureus isolates from keratitis and conjunctivitis. Am J Ophthalmol. 2004;137(3):453-458.

75. Blomquist PH. Methicillin-resistant Staphylococcus aureus infections of the eye and orbit (an American Ophthalmological Society thesis). Trans Am Ophthalmol Soc. 2006;104:322-345.

76. McDonald MB, Blondeau JM, DeCory HH, et al. Multidrug-resistant strains in clinical trials of besifloxacin in the treatment of bacterial conjunctivitis. Presented at the American Academy of Ophthalmology Annual Meeting; 2008 Nov 8-11; Atlanta, GA, USA.Poster 070.

77. Buznach N, Dagan R, Greenberg D. Clinical and bacterial characteristics of acute bacterial conjunctivitis in children in the antibiotic resistance era. Pediatr Infect Dis J. 2005;24(9):823-828.

78. Ohnsman C, Ritterband D, O'Brien T, Girgis D, Kabat A. Comparison of azithromycin and moxifloxacin against bacterial isolates causing conjunctivitis. Curr Med Res Opin. 2007;23(9):2241-2249. 
79. Lichtenstein SJ, Wagner RS, Jamison T, Bell B, Stroman DW. Speed of bacterial kill with a fluoroquinolone compared with nonfluoroquinolones: clinical implications and a review of kinetics of kill studies. Adv Ther. 2007;24(5):1098-1111.

80. Chalita MR, Hofling-Lima AL, Paranhos A Jr, Schor P, Belfort R Jr. Shifting trends in in vitro antibiotic susceptibilities for common ocular isolates during a period of 15 years. Am J Ophthalmol. 2004;137(1): 43-51.

81. Oliveira AD, D'Azevedo PA, Francisco W. In vitro activity of fluoroquinolones against ocular bacterial isolates in Sao Paulo, Brazil. Cornea. 2007;26(2):194-198.

82. Afshari NA, Ma JJ, Duncan SM, et al. Trends in resistance to ciprofloxacin, cefazolin, and gentamicin in the treatment of bacterial keratitis. J Ocul Pharmacol Ther. 2008;24(2):217-223.

83. Tuft SJ, Matheson M. In vitro antibiotic resistance in bacterial keratitis in London. Br J Ophthalmol. 2000;84(7):687-691.

84. Parmar P, Salman A, Kalavathy CM, et al. Comparison of topical gatifloxacin $0.3 \%$ and ciprofloxacin $0.3 \%$ for the treatment of bacterial keratitis. Am J Ophthalmol. 2006;141(2):282-286.

85. Wilhelmus KR, Abshire RL, Schlech BA. Influence of fluoroquinolone susceptibility on the therapeutic response of fluoroquinolone-treated bacterial keratitis. Arch Ophthalmol. 2003;121(9):1229-1233.

86. Moshirfar M, Mirzaian G, Feiz V, Kang PC. Fourth-generation fluoroquinolone-resistant bacterial keratitis after refractive surgery. $J$ Cataract Refract Surg. 2006;32(3):515-518.

87. Miller D, Flynn PM, Scott IU, Alfonso EC, Flynn HW Jr. In vitro fluoroquinolone resistance in staphylococcal endophthalmitis isolates. Arch Ophthalmol. 2006;124(4):479-483.

88. Asbell PA, Sahm DF. Longitudinal nationwide antimicrobial susceptibility surveillance in ocular isolates: results from Ocular TRUST 2. Presented at: American Society of Cataract and Refractive Surgery Annual Meeting; 2007 April 27-May 2; San Diego, CA, USA.

89. Morrissey I, Burnett R, Viljoen L, Robbins M. Surveillance of the susceptibility of ocular bacterial pathogens to the fluoroquinolone gatifloxacin and other antimicrobials in Europe during 2001/2002. J Infect. 2004;49(2):109-114.

90. Brown L. Resistance to ocular antibiotics: an overview. Clin Exp Optom. 2007;90(4):258-262.

91. Tzepi I, Vergados I, Kanellakopoulou K, et al. Pharmacokinetics of intravenously administered moxifloxacin in eye compartments: an experimental study. Int J Antimicrob Agents. 2009;33(2):160-162.

92. Wise R, Andrews J. The bactericidal activity of gatifloxacin in plasma and urine. Clin Microbiol Infect. 1998;4(7):392-396.

93. Drusano GL. Pharmacokinetics and pharmacodynamics of antimicrobials. Clin Infect Dis. 2007;45(Suppl 1):S89-S95.

94. Ambrose PG, Bhavnani SM, Rubino CM, et al. Pharmacokineticspharmacodynamics of antimicrobial therapy: it's not just for mice anymore. Clin Infect Dis. 2007;44(1):79-86.

95. Wright DH, Brown GH, Peterson ML, Rotschafer JC. Application of fluoroquinolone pharmacodynamics. J Antimicrob Chemother. 2000; 46(5):669-683.

96. Firsov AA, Lubenko IY, Vostrov SN, Portnoy YA, Zinner SH. Antistaphylococcal effect related to the area under the curve/MIC ratio in an in vitro dynamic model: predicted breakpoints versus clinically achievable values for seven fluoroquinolones. Antimicrob Agents Chemother. 2005;49(7):2642-2647.

97. Blondeau JM, Zhao X, Hansen G, Drlica K. Mutant prevention concentrations of fluoroquinolones for clinical isolates of Streptococcus pneumoniae. Antimicrob Agents Chemother. 2001;45(2):433-438.

98. Metzler K, Hansen GM, Hedlin P, Harding E, Drlica K, Blondeau JM. Comparison of minimal inhibitory and mutant prevention drug concentrations of 4 fluoroquinolones against clinical isolates of methicillin-susceptible and -resistant Staphylococcus aureus. Int J Antimicrob Agents. 2004;24(2):161-167.

99. Drusano GL, Louie A, Deziel M, Gumbo T. The crisis of resistance: identifying drug exposures to suppress amplification of resistant mutant subpopulations. Clin Infect Dis. 2006;42(4):525-532.
100. Tam VH, Louie A, Fritsche TR, et al. Impact of drug-exposure intensity and duration of therapy on the emergence of Staphylococcus aureus resistance to a quinolone antimicrobial. J Infect Dis. 2007; 195(12):1818-1827.

101. Robertson SM, Curtis MA, Schlech BA, et al. Ocular pharmacokinetics of moxifloxacin after topical treatment of animals and humans. Surv Ophthalmol. 2005;50 (Suppl 1):S32-S45.

102. Quixin [package insert]. Jacksonville, FL; Vistakon Pharmaceuticals LLC; April 2006.

103. Blondeau JM. Fluoroquinolones: mechanism of action, classification, and development of resistance. Surv Ophthalmol. 2004;49(Suppl 2): S73-S78.

104. Ward KW, Lepage JF, Driot JY. Nonclinical pharmacodynamics, pharmacokinetics, and safety of BOL-303224-A, a novel fluoroquinolone antimicrobial agent for topical ophthalmic use. J Ocul Pharmacol Ther. 2007;23(3):243-256.

105. Cambau E, Matrat S, Pan XS, et al. Target specificity of the fluoroquinolone besifloxacin in Streptococcus pneumoniae, Staphylococcus aureus and Escherichia coli.JAntimicrob Chemother. 2009;63(3):443-450.

106. Brunner LS, Norton SE, Blondeau JM. In vitro activity of SS734, a novel fluoroquinolone, against pathogens associated with bacterial conjunctivitis. [poster] 17th European Congress of Clinical Microbiology and Infectious Diseases; March 31-April 3, 2007; Munich, Germany. Poster P1679.

107. Proksch JW, Driot JY, Ward KW. Nonclinical ocular and systemic pharmacokinetics of BOL-303224-A, a novel fluoroquinolone antimicrobial agent for topical ophthalmic use. Presented at the Association for Research in Vision and Ophthalmology Annual Meeting; 2007 Apr 27-May 1; Fort Lauderdale, FL, USA. Poster \#B654.

108. Chappa AK, Proksch JW, Ward KW. Comparison of the ocular and systemic pharmacokinetics of besifloxacin, a novel fluoroquinolone antibiotic, with moxifloxacin and gatifloxacin in pigmented rabbits. Presented at the Association for Research in Vision and Ophthalmology Annual Meeting; 2008 Apr 27-May 1; Fort Lauderdale, FL, USA. Poster \#D684.

109. Zhang JZ, Cavet ME, Ward KW. Anti-inflammatory effects of besifloxacin, a novel fluoroquinolone, in primary human corneal epithelial cells. Curr Eye Res. 2008;33(11):923-933.

110. Zhang JZ, Ward KW. Besifloxacin, a novel fluoroquinolone antimicrobial agent, exhibits potent inhibition of pro-inflammatory cytokines in human THP-1 monocytes. J Antimicrob Chemother. 2008;61(1):111-116.

111. Granvil CP, Siou-Mermet R, Comstock T, Jonasse M, Proksch JW. Ocular pharmacokinetics of besifloxacin, a novel fluoroquinolone antimicrobial agent for topical ophthalmic use, in healthy volunteers. Presented at the Association for Research in Vision and Ophthalmology Annual Meeting; 2008 Apr 27-May 1; Fort Lauderdale, FL, USA. Poster \#D691.

112. Proksch J, Granvil CP, Siou-Mermet R, Comstock T, Paterno M, Ward KW. Ocular pharmacokinetics of besifloxacin following topical administration to rabbits, monkeys, and humans. J Ocul Pharm Ther. 2009;25(4):335-341.

113. Liu Z, Li J, Nie S, Liu H, Ding P, Pan W. Study of an alginate/HPMCbased in situ gelling ophthalmic delivery system for gatifloxacin. Int J Pharm. 2006;315(1-2):12-17.

114. Mansour M, Mansour S, Mortada ND, Abd Elhady SS. Ocular poloxamer-based ciprofloxacin hydrochloride in situ forming gels. Drug Dev Ind Pharm. 2008;34(7):744-752.

115. Abraham S, Furtado S, Bharath S, Basavaraj BV, Deveswaran R, Madhavan V. Sustained ophthalmic delivery of ofloxacin from an ion-activated in situ gelling system. Pak J Pharm Sci. 2009;22(2):175-179.

116. Karpecki P, DePaolis M, Hunter JA, et al. Besifloxacin ophthalmic suspension $0.6 \%$ in patients with bacterial conjunctivitis: a multicenter, prospective, randomized, double-masked, vehicle-controlled, 5-day efficacy and safety study. Clin Ther. 2009;31(3):514-526. 
117. Tepedino ME, Heller WH, Usner DW, et al. Phase III efficacy and safety study of besifloxacin ophthalmic suspension $0.6 \%$ in the treatment of bacterial conjunctivitis. Curr Med Res Opin. 2009;25(5):1159-1169.

118. McDonald MB, Protzko EE, Brunner LS, et al. Efficacy and safety of besifloxacin ophthalmic suspension $0.6 \%$ compared with moxifloxacin ophthalmic solution $0.5 \%$ for treating bacterial conjunctivitis. Ophthalmology. 2009;116(9):1615-1623.

119. Antibiotic/Antimicrobial Resistance: Clinical guidelines. Available at: http://www.cdc.gov/DRUGRESISTANCE/clinical.htm. Accessed Dec. 5, 2008.
120. World Health Organization. Antimicrobial resistance. Available at: http://www.who.int/mediacentre/factsheets/fs194/en/print.html. 2002; Fact sheet 194. Accessed Dec. 5, 2008.

121. Yoneyama H, Katsumata R. Antibiotic resistance in bacteria and its future for novel antibiotic development. Biosci Biotechnol Biochem. 2006;70(5):1060-1075.

\section{Publish your work in this journal}

Clinical Ophthalmology is an international, peer-reviewed journal covering all subspecialties within ophthalmology. Key topics include: Optometry; Visual science; Pharmacology and drug therapy in eye diseases; Basic Sciences; Primary and Secondary eye care; Patien Safety and Quality of Care Improvements. This journal is indexed on

Submit your manuscript here: http://www.dovepress.com/clinical-ophthalmology-journal

\section{Dovepress}

PubMed Central and CAS, and is the official journal of The Society of Clinical Ophthalmology (SCO). The manuscript management system is completely online and includes a very quick and fair peer-review system, which is all easy to use. Visit http://www.dovepress.com/ testimonials.php to read real quotes from published authors. 